\title{
GABUNGAN KOMBINASI PROPOSISI (REKURSIF) DALAM KUMPULAN CERITA PENDEK RECTOVERSO KARANGAN DEE
}

\author{
Aji Bagoes Risang Panengah \\ Krisanjaya \\ Edi Puryanto
}

\begin{abstract}
Abstrak. Penelitian ini bertujuan untuk memperoleh informasi mengenai gabungan kombinasi proposisi (rekursif) dalam kumpulan cerita pendek Rectoverso karangan Dee. Metode yang digunakan dsalam penelitian ini adalah metode deskriptif kualitatif dengan teknik analisis isi.Penelitian ini difokuskan pada pola-pola gabungan kombinasi proposisi atau rekursif dalam wacana kumpulan cerita pendek Rectoverso karangan Dee. Berdasarkan analisis data yang dilakukan, maka diperoleh hasil penelitian sebagai berikut.Kumpulan cerita pendek Rectoverso karya Dee menggunakan dua pola gabungan kombinasi proposisi (rekursif) yaitu pola 1 atau gabungan antara kombinasi proposisi koordinasi dan relativisasi dan pola 2 atau gabungan kombinasi proposisi koordinasi dan komplementasi. Sedangkan pola 3 atau gabungan kombinasi proposisi relativisasi dan komplementasi sama sekali tidak muncul. Pola gabungan kombinasi proposisi (rekursif) yang paling banyak muncul adalah pola 1 atau gabungan antara kombinasi proposisi proposisi koordinasi dan kombinasi proposisi relativisasi yaitu sebanyak 87,5\%. Sementara itu, pola 2 atau gabungan kombinasi proposisi koordinasi dan komplementasi digunakan sebanyak 12,5\%. Dominasi kemunculan pola 1 gabungan kombinasi proposisi (rekursif) disebabkan karena penulis banyak menggunakan bentuk kombinasi proposisi koordinasi untuk menghubungkan proposisi-proposisinya dengan menggunakan konjungsi koordinatif karena cara tersebut merupakan bentuk pengombinasian yang paling mudah. Selain itu, penulis juga banyak menggunakan kombinasi proposisi relativisasi untuk membatasi proposisi agar maksud yang ingin disampaikan tidak melebar dan lebih fokus dengan cara membatasi bagiannya. Kombinasi proposisi koordinasi dan relativisasi yang telah digunakan kemudian dipadukan kembali dengan cara rekursif sehingga terbentuklah pola 1 gabungan kombinasi proposisi.
\end{abstract}

Kata Kunci: Kombinasi Proposisi, Gabungan Kombinasi Proposisi, Cerita Pendek

\section{PENDAHULUAN}

Bahasa merupakan hasil berpikir yang memegang peranan penting dalam kehidupan manusia dan merupakan ciri pembeda utama antara manusia dengan makhluk hidup lain yang ada di dunia. Bahasa merupakan salah satu alat komunikasi manusia sehingga manusia dapat saling mengerti antarindividu.Bahasa membantu manusia dalam menyampaikan informasi yang faktual dan proporsional.Dengan bahasa, pembicara dapat menyampaikan pesan pada pendengar dengan efektif sehingga pendengar dapat menerima rincian informasi yang benar.

Komunikasi merupakan hal yang sangat penting dalam kehidupan bermasyarakat agar manusia dapat bersosialisasi dengan orang-orang yang ada di sekitar mereka. Dalam 
bersosialisasi, manusia membutuhkan ujaran untuk dapat menyampaikan apa yang ada di benaknya kepada orang lain.

Saat seseorang menggunakan bahasa, terjadilah proses mental dalam produksi dan persepsi bahasa sehingga akhirnya muncul kalimat yang efektif dan dapat dimengerti oleh lawan bicara. Kalimat-kalimat tersebut terbentuk dari proposisi-proposisi yang ada dalam benak pembicara. Ujaran akan terasa sangat aneh dan berbelit-belit apabila dalam tiap kalimatnya hanya memiliki satu proposisi. Setiap kalimat akan menjadi pendek dan tidak berkaitan dengan kalimat lainnya. Hal itu menyebabkan ketidakefektifan dalam berkomunikasi.

Pembicara akan memerlukan waktu yang panjang untuk mengutarakan apa yang ada di benaknya dan pendengar akan sulit untuk mencerna dan memahami kalimat-kalimat yang diujarkan oleh pembicara. Maka dari itu, pembicara memerlukan kombinasi proposisi yang akan menghubungkan kalimat satu dengan yang lainnya sehingga lebih mudah dimengerti.

Kombinasi proposisi sangat membantu manusia dalam berkomunikasi dan bersosialisasi satu sama lain, sehingga pembicara akan lebih mudah dan tidak memerlukan waktu yang panjang untuk mengutarakan apa yang ada di benaknya. Pendengar juga dapat lebih mudah mencerna dan memahami apa yang pembicara utarakan.

Dalam bahasa, terdapat tiga cara dalam mengombinasikan proposisi. Ketiga cara tersebut adalah koordinasi, relativisasi, dan komplementasi. Koordinasi adalah proses kombinasi proposisi yang menghubungkan dua buah proposisi dengan menggunakan konjungsi koordinatif. Relativisasi adalah proses kombinasi proposisi dengan cara memasukkan salah satu proposisi ke dalam bagian proposisi yang lain agar proposisi tersebut dapat dibatasi atau dikualifikasi bagian-bagiannya. Herbert H. Clark dan Eve V. Clark dalam bukunya Psychology and Language menjelaskan Komplementasi adalah proses kombinasi proposisi dengan cara menggunakan salah satu proposisi untuk mengisi bagian yang kosong dari proposisi yang lain. Dalam satu kalimat, pengombinasian proposisi dapat menggunakan lebih dari satu cara. Pengombinasian proposisi dengan menggunakan lebih dari satu cara dalam satu kalimat, disebut dengan rekursif (Herbert $\mathrm{H}$. Clark dan Eve V. Clark, 1977:14). Kombinasi-kombinasi proposisi tersebut membuat komunikasi antara pembicara dan pendengar menjadi lebih mudah.

Menurut Samsuniwiyati Mar'at ada dua cara dalam persepsi dan produksi bahasa, yaitu secara auditif dan visual. Persepsi bahasa secara auditif adalah mendengarkan dan persepsi bahasa secara visual adalah membaca. Dalam produksi bahasa, kegiatannya adalah berbicara (auditif) dan menulis (visual) (Samsuniwiyati Mar'at, 2011: 1). Produksi dan persepsi bahasa secara visual, yaitu menulis dan membaca, juga digunakan dalam menulis dan membaca karya fiksi seperti cerita pendek dan novel. Dalam cerita pendek maupun novel, penulis ingin mengutarakan apa yang ada dipikirannya. Agar apa yang ingin disampaikan penulis dapat tersampaikan dengan pembaik kepada pembaca, penulis harus mengombinasikan proposisi-proposisi yang ingin diutarakannya dengan benar.

Sebuah karya fiksi yang baik tentunya menggunakan bahasa yang baik sehingga pembaca dapat menangkap apa yang ingin disampaikan oleh penulis dengan baik pula. Karya fiksi yang baik akan menggunakan kombinasi proposisi dalam penulisannya sehingga pembaca akan lebih mudah memahami isi dari karya fiksi tersebut.

Berdasarkan apa yang telah dipaparkan, peneliti tertarik untuk meneliti bentukbentuk kombinasi proposisi dan juga gabungan kombinasi proposisi (rekursif) yang digunakan pengarang dalam sebuah karya fiksi. Sebagai mahasiswa Jurusan Bahasa dan 
Sastra Indonesia, tidak dapat dipungkiri, peneliti dan mahasiswa lain yang menempuh pendidikan di jurusan ini, tentu memiliki ketertarikan tersendiri terhadap karya sastra seperti puisi, cerpen, dan novel, bahkan juga memiliki keinginan untuk dapat menulis karya sastra dengan bahasa yang baik dan efektif sehingga karya sastra tersebut dapat diterbitkan sehingga akhirnya karya tersebut dapat dikenal luas dan banyak disukai pembaca.

Untuk itu, dengan adanya penelitian mengenai kombinasi proposisi dan gabungan kombinasi proposisi dalam karya sastra ini, dapat ditemukan contoh bentuk-bentuk pengombinasian yang dilakukan oleh pengarang yang sudah berpengalaman dalam menulis karya sastra yang sukses dan disukai pembaca. Bentuk-bentuk kombinasi proposisi yang ditemukan dapat dijadikan pembelajaran untuk pembaca penelitian ini, khususnya mahasiswa Jurusan Bahasa dan Sastra Indonesia dan orang lain yang tertarik untuk membuat karya sastra dengan bahasa yang efektif sehingga maksud yang ingin disampaikan oleh penulis dapat tersampaikan dengan baik kepada pembaca. Penelitian ini juga diharapkan dapat memberi pengetahuan bahwa pada saat menulis karya sastra, kalimat-kalimat yang diungkapkan bukan kalimat yang begitu saja muncul, namun juga telah melalui proses pengombinasian proposisi yang telah dilakukan oleh penulis karya tersebut.

Objek yang akan diteliti dalam penelitian ini adalah buku kumpulan cerita pendek Rectoverso karya Dee atau Dewi Lestari yang terdiri dari sebelas cerita pendek, yaitu Curhat buat Sahabat, Malaikat Juga Tahu, Selamat Ulang Tahun, Aku Ada, Hanya Isyarat, Peluk, Grow a Day Older, Cicak di Dinding, Firasat, Tidur, dan Back to Heaven's Light.

Peneliti memilih objek tersebut karena kumpulan cerita pendek Rectoverso merupakan salah satu karya sastra yang terkenal dan banyak disukai pembaca.Rectoverso yang mendapat respon positif oleh pembaca akhirnya diangkat menjadi sebuah film omnibus yang juga berjudul Rectoverso. Namun, dalam film tersebut hanya mengangkat lima cerita pendek terbaik dari buku Rectoverso, yaitu Malaikat Juga Tahu, Curhat buat Sahabat, Cicak di Dinding, Firasat, dan Hanya Isyarat. Film tersebut berhasil memperoleh penjualan yang cukup baik dan juga berhasil mendapat tanggapan positif dari kritikus dan penonton.

Kombinasi proposisi dan gabungan kombinasi proposisi dalam buku kumpulan cerita pendek Rectoverso tentu membuat pembaca menjadi lebih mudah mencerna dan memahami apa yang ingin disampaikan oleh penulisnya. Hal tersebut menarik perhatian penulis untuk melihat bagaimana bentuk-bentuk gabungan kombinasi proposisi (rekursif), yang terbangun dari kombinasi proposisi koordinasi, relativisasi, dan komplementasi, yang digunakan oleh pengarang Rectoverso. Berdasarkan apa yang telah dipaparkan, maka peneliti mengangkat judul "Gabungan Kombinasi Proposisi (Rekursif) dalam Kumpulan Cerita Pendek Rectoverso Karangan Dee”.

\section{METODE PENELITIAN}

Metode yang digunakan dalam penelitian ini adalah metode deskriptif kualitatif dengan teknik analisis isi. 


\section{HASIL PENELITIAN}

Kumpulan cerita pendek Rectoverso karya Dee menggunakan dua pola gabungan kombinasi proposisi (rekursif) yaitu pola 1 atau gabungan antara kombinasi proposisi koordinasi dan relativisasi dan pola 2 atau gabungan kombinasi proposisi koordinasi dan komplementasi. Sedangkan pola 3 atau gabungan kombinasi proposisi relativisasi dan komplementasi sama sekali tidak muncul.

Gabungan kombinasi proposisi (rekursif) dalam kumpulan cerita pendek Rectoverso didominasi oleh pola 1 atau gabungan kombinasi proposisi koordinasi dan relativisasi yaitu sebanyak 87,5\%. Dalam menulis kumpulan cerita pendek Rectoverso, penulis banyak menggunakan bentuk kombinasi proposisi koordinasi untuk menghubungkan proposisi-proposisinya dengan menggunakan konjungsi koordinatif karena cara tersebut merupakan bentuk pengombinasian yang paling mudah. Selain itu, penulis juga banyak menggunakan kombinasi proposisi relativisasi untuk membatasi proposisi agar maksud yang ingin disampaikan tidak melebar dan lebih fokus dengan cara membatasi bagiannya. Kombinasi proposisi koordinasi dan relativisasi yang telah digunakan kemudian dipadukan kembali dengan cara rekursif sehingga terbentuklah pola 1 gabungan kombinasi proposisi. Pola inilah yang sering dilakukan penulis sehingga jumlah kemunculan pola ini jauh di atas pola gabungan kombinasi proposisi lainnya.

Pola gabungan kombinasi proposisi terbanyak kedua adalah pola 2 atau gabungan antara kombinasi proposisi koordinasi dan komplementasi.Cara ini jarang dilakukan karena kemunculan kombinasi proposisi komplementasi sendiri sangat jarang muncul dalam kumpulan cerita pendek Rectoverso karya Dee ini.Hal itu disebabkan kombinasi proposisi komplementasi cukup sulit digunakan karena biasanya salah satu argumen atau predikasinya merujuk ke kalimat sebelumnya atau setelahnya. Maka dari itu, penggunaan gabungan kombinasi proposisi relativisasi dan komplementasi ini pun sangat sedikit ditemukan di kumpulan cerita pendek Rectoverso ini yaitu hanya sebanyak 12,5\%. Jumlah tersebut sangat kontras jika dibandingkan dengan penggunaan pola 1 gabungan kombinasi proposisi (rekursif).

Sementara itu, pola 3 gabungan kombinasi proposisi (rekursif) yaitu gabungan antara kombinasi proposisi koordinasi dan komplementasi sama sekali tidak ditemukan dalam kumpulan cerita pendek Rectoverso. Penulis lebih memilih menggunakan pola 1 dan pola 2 untuk menghubungkan proposisi-proposisi yang ada di benaknya.

Dalam melakukan penelitian ini, peneliti juga menemukan bentuk-bentuk lain yang dilakukan penulis Rectoverso saat menempatkan dua proposisi dalam satu kalimat.Bentukbentuk tersebut tidak ditemukan dalam teori kombinasi proposisi Herbert H. Clark dan Eve V. Clark. Bentuk yang pertama adalah penempatan dua proposisi dalam satu kalimat dengan menggunakan konjungsi lain selain konjungsi koordinatif untuk menghubungkan dua proposisinya. Contohnya pada kalimat "Hujan menggelontor sampai dahan-dahan pohon tua di jalanan rumahku rontok seperti daun kering."Kalimat tersebut terdiri dari dua proposisi, yaitu Hujan (Argumen) menggelontor (Predikasi)dan Dahan-dahan pohon tua di rumahku (Argumen) rontok (Predikasi). Namun, kalimat tersebut menggunakan konjungsi subordinatif sampai untuk menghubungkan dua proposisinya.

Bentuk yang kedua adalah penempatan dua proposisi dalam satu kalimat dengan menggunakan tanda "," (koma) untuk menghubungkan dua proposisinya.Contohnya pada kalimat "Entah hijau, entah coklat muda."Kalimat tersebut terdiri dari dua proposisi, yaitu 
Entah (Predikasi) hijau (Argumen)dan entah (Predikasi) cokelat muda (Argumen).Namun, kalimat tersebut menggunakan tanda "," (koma) untuk menghubungkan dua proposisinya.

Berdasarkan apa yang telah dipaparkan, dapat disimpulkan bahwa kumpulan cerita pendek Rectoverso karya Dee menggunakan gabungan kombinasi proposisi (rekursif), yaitu pola 1 atau gabungan kombinasi proposisi koordinasi dan relativisasi dan pola 2 atau gabungan kombinasi proposisi koordinasi dan kombinasi proposisi komplementasi. Gabungan kombinasi proposisi (rekursif) ini terbentuk dari kombinasi-kombinasi proposisi yang membantu penulis dalam melakukan produksi bahasa secara visual, untuk menghubungkan proposisi-proposisi yang ada di benaknya sehingga menjadi kalimat yang efektif dan dapat dengan mudah dipahami oleh pembaca. Hal tersebut menandakan bahwa untuk menulis karya sastra yang baik dan dapat disukai pembaca diperlukan kombinasi proposisi serta gabungan kombinasi proposisi (rekursif) karena dengan cara tersebut kalimat yang terbentuk menjadi efektif dan tidak berbelit-belit sehingga pembaca pun dapat dengan mudah memahami apa yang ingin disampaikan oleh penulis.

Dalam melakukan penelitian ini, peneliti juga menemukan bentuk-bentuk lain yang dilakukan penulis Rectoverso saat menempatkan dua proposisi dalam satu kalimat.Bentukbentuk tersebut tidak ditemukan dalam teori kombinasi proposisi Herbert H. Clark dan Eve V. Clark.Bentuk yang pertama adalah penempatan dua proposisi dalam satu kalimat dengan menggunakan konjungsi lain selain konjungsi koordinatif untuk menghubungkan dua proposisinya dan bentuk yang kedua adalah penempatan dua proposisi dalam satu kalimat dengan menggunakan tanda "," (koma) untuk menghubungkan dua proposisinya.

\section{KESIMPULAN}

Berdasarkan penelitian, ditemukan bahwa pada kumpulan cerita pendek Rectoverso karangan Dee yang diteliti, yaitu empat cerita pendek berjudul Curhat buat Sahabat, Malaikat Juga Tahu, Hanya Isyarat, dan Cicak di Dinding ditemukan 8 bentuk gabungan kombinasi proposisi (rekursif). Kumpulan cerita pendek Rectoverso karya Dee menggunakan dua pola gabungan kombinasi proposisi (rekursif) yaitu pola 1 atau gabungan antara kombinasi proposisi koordinasi dan relativisasi dan pola 2 atau gabungan kombinasi proposisi koordinasi dan komplementasi. Sedangkan pola 3 atau gabungan kombinasi proposisi relativisasi dan komplementasi sama sekali tidak muncul.

Penulis kumpulan cerita pendek Rectoverso paling sering menggunakan pola 1 gabungan kombinasi proposisi (rekursif) atau gabungan antara kombinasi proposisi proposisi koordinasi dan kombinasi proposisi relativisasi yaitu sebanyak 87,5\%. Sementara itu, pola 2 gabungan kombinasi proposisi (rekursif) atau gabungan kombinasi proposisi koordinasi dan komplementasi digunakan sebanyak 12,5\%. Dominasi kemunculan pola 1 gabungan kombinasi proposisi (rekursif) disebabkan karena penulis banyak menggunakan bentuk kombinasi proposisi koordinasi untuk menghubungkan proposisi-proposisinya dengan menggunakan konjungsi koordinatif karena cara tersebut merupakan bentuk pengombinasian yang paling mudah. Selain itu, penulis juga banyak menggunakan kombinasi proposisi relativisasi untuk membatasi proposisi agar maksud yang ingin disampaikan tidak melebar dan lebih fokus dengan cara membatasi bagiannya. Kombinasi proposisi koordinasi dan relativisasi yang telah digunakan kemudian dipadukan kembali dengan cara rekursif sehingga terbentuklah pola 1 gabungan kombinasi proposisi. 
Arkhais, Vol. 07 No. 2 Jufi - Desember 2016

Dalam melakukan penelitian ini, peneliti juga menemukan bentuk-bentuk lain yang dilakukan penulis Rectoverso saat menempatkan dua proposisi dalam satu kalimat. Bentukbentuk tersebut tidak ditemukan dalam teori kombinasi proposisi Herbert H. Clark dan Eve V. Clark. Bentuk yang pertama adalah penempatan dua proposisi dalam satu kalimat dengan menggunakan konjungsi lain selain konjungsi koordinatif untuk menghubungkan dua proposisinya dan bentuk yang kedua adalah penempatan dua proposisi dalam satu kalimat dengan menggunakan tanda "," (koma) untuk menghubungkan dua proposisinya.

\section{DAFTAR RUJUKAN}

Aitchison, Jean. 1998. The Articulate Mammal: An Introduction to Psycholinguistics. London: Routledge.

Chaer, Abdul. 2009. Psikolinguistik: Kajian Teoretik. Jakarta: Rineka Cipta.

Clark, Herbert H. dan Clark, Eve V. 1977. Psychology and Language. New York: Harcourt Brace Jovanovich, Inc.

Dardjowidjojo, Soenjono. 2005. Psikolinguistik: Pengantar Pemahaman Bahasa Manusia. Jakarta: Yayasan Obor Indonesia.

Djajasudarma, Fatimah. 1993. Metode Linguistik: Ancangan Metode Penelitian dan Kajian. Bandung: Eresco.

Harley, Trevor A. 2001. The Psychology of Language: From Data to Theory. Hove: Psychology Press.

Lobner, Sebastian. 2002. Understanding Semantics. London: Arnold.

Mahsun, M. S. 2005. Metode Penelitian Bahasa. Jakarta: Rajagrafindo.

Mar'at, Samsuniwiyati. 2011. Psikolinguistik: Suatu Pengantar. Bandung: Refika Aditama.

Moleong, Lexy J. 1993. Metodologi Penelitian Kualitatif. Bandung: Rosdakarya.

Muhadjir, Noeng. 1989. Metode Penelitian Kualitatif. Yogykarta: Rake Sarasin.

Putrayasa, Ida Bagus. 2010. Analisis Kalimat. Bandung: Refika Aditama. . 2012. Jenis Kalimat dalam Bahasa Indonesia. Bandung: Refika Aditama. 